\title{
Women, the silent champions: Time to close the gender gap in biodiversity
}

\author{
Mária Bajner \\ University of Pécs, Hungary \\ E-mail: bajner@kpvk.pte.hu
}

\begin{abstract}
The paper attempts to identify the common links between gender equality and sustainable agriculture, with special focus on biodiversity in the developing countries and call attention to the issues that affect women more than men. Gender inequality in agriculture may substantially reduce the ability of societies to conserve biodiversity and herewith maintain or increase the carrying capacity of ecosystem services due to different approaches between women and men to management of natural resources, agricultural cultivation methods and food production. Thus, biodiversity conservation approaches need to be promoted with reliance on traditional conservation approaches applied by women. Therefore, more female representatives from the highest to the lowest legislative bodies would be beneficial to support the interest of the stakeholders, since their majority especially at the effective farming end - are women.
\end{abstract}

Keywords - women, gender gap, biodiversity, sustainable development goals

\section{INTRODUCTION}

According to The Global Gender Gap Report of the World Economic Forum (2018) out of 149 countries assessed, 34\% of women hold managerial positions and less than $7 \%$ belongs to the worst-performing countries. Women have as much access to financial services as men in just $60 \%$ of the countries, and to land ownership in only $42 \%$ of the countries assessed. Among the 29 countries - for which data are available - women spend, on average, twice as much time on housework and other unpaid activities than men. In Western Europe (with 75.8\% gender parity) and North America $(72.5 \%)$ - where gender advocates are allowed to make their voices heard - and women's participation and opportunity in the decision-making is advancing, the "gender gap" has been reduced. In countries where women still encounter significant obstacles in economic and political empowerment gender disparity is the largest. The score for gender parity is $66.3 \%$ in Sub-Saharan Africa, $65.8 \%$ in South Asia, and $60.2 \%$ in the Middle East and North Africa (World Economic Forum 2018).
It follows from what precedes that Sustainable Development Goals (United Nations 2018) referring to embedded gender issues, i.e. equal rights and access to ownership and control over land, good health, and well-being, zero-hunger, or gender equality are among the main targets to achieve.

The paper attempts to identify the common links between gender equality and sustainable agriculture, with special focus on biodiversity in the developing countries mentioned above and call attention to the issues that affect women more than men and therefore should constitute a particularly important part of new socio-economic and environmental strategies. According to the Biodiversity-Ecosystem Function (BEF) theory, all levels of ecosystem functions, such as primary and secondary productivity, nutrient cycling, decomposition, etc. and the stability of those functions depend directly on biodiversity at the level of genotypes, species and functional groups, which may be regarded as assemblages of physiologically similar species. Thus, the maintenance of healthy agro-ecosystems depends on the carrying capacity of ecosystem services. 


\section{Gender Issues among the 2030 Agenda Goals}

Although in the Report (Transforming our world the 2030 Agenda for Sustainable Development) of the United Nations Population Fund (2015) some indicators of gender equality are progressing, insufficient progress on structural issues at the root of gender inequality, such as decision making and low level of political participation show very little (if any) level of improvement. Stakeholder engagement in sustainable development requires active participation of all sectors of society and all types of people, including women, who are underrepresented in political and economic decision-making processes. If we are to address the gender dimension it is essential to note that globally, women are just $13 \%$ of agricultural land holders (The Economist Intelligence Unit 2019). Women in Northern Africa hold less than one in five paid jobs in the non-agricultural sector. The proportion of women in paid employment outside the agriculture sector has increased from 35 percent in 1990 to 41 per cent in 2015 (United Nations 2019a).

The Zero Hunger Challenge of the United Nations (2019b) promotes gender equality by recognizing the interlinkage among supporting sustainable agriculture, ensuring healthy lifestyles, empowering local stakeholders and gender equality. Gender equality and women's empowerment is addressed in many UN documents in order to abolish all forms of discrimination against women. As stated in Goal 5. in the Sustainable Development objectives: "UN Women works for the elimination of discrimination against women and girls, empowerment of women, and achievement of equality between women and men as partners and beneficiaries of development, human rights, humanitarian action and peace and security." And - as it stated in The Sustainable Development Goals Report (United Nations 2018) - "while some forms of discrimination against women are declining, gender inequality continues to hold women back and deprives them of basic rights and opportunities".

The environmental problems in the agricultural sector are particularly emphasized in these countries with widespread poverty, political instability, and fragile, underdeveloped agricultural systems, which are likely to be further exacerbated with accelerating climate change and depletion of natural resources (Brown and Funk 2008). One of the main problems is soil degradation caused by monoculture and extensive use of agrochemicals (fertilizers and pesticides, some of them are banned from Europe). Biodiversity Ecosystem Functions (BEF) are interpreted as a subset of ecological processes and ecosystem structures, which are typically estimated from measures of stocks such as plant biomass or crop nutrients and aboveground - belowground interactions in response to vascular plant diversity (Némethy and Szemethy 2019; Fig. 1).

In many developing countries women carry the main responsibility to obtain primary resources such as drinking water, raw material for food, edible plants, herbs and medical plants, firewood, preparation of food, etc. while they are not represented in decision making bodies due to certain "frozen" gender roles.

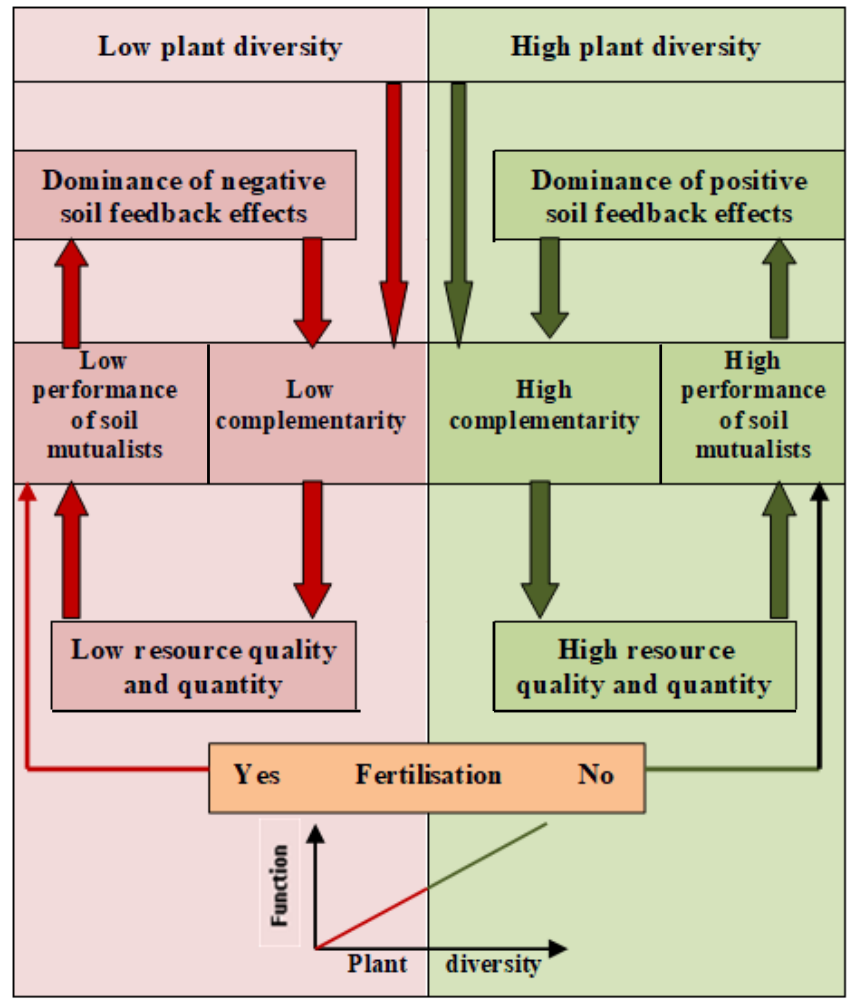

Figure 1. The influence of aboveground - belowground interactions on the positive relationship between biodiversity and ecosystem functioning. Resource use complementarity is higher in high communities with high plant diversity. Mutualists will mitigate or superimpose adverse effects of antagonists on plants). Artificial fertilisation may have negative effect on the performance of soil mutualists, such as arbuscular mycorrhiza fungi (Collins Johnson, 1993). Source: Némethy and Szemethy (2019) redrawn and modified after Eisenhauer (2018).

\section{Traditional gender roles designed for women in agriculture}

This issue is all the more important in view of the traditions that women are the frontrunners, the agents of change who build pathways to accelerate transitions to sustainability. In developing countries, biodiversity loss and gender-blind conservation measures put an excessive burden on women by increasing the time necessary to obtain primary resources, such as food, water or medical plants (Dilys et al. 2019).

In situations where water must be collected outside the home, women bear primary responsibility. A study (Jaworski 2019) of 25 sub-Saharan countries found that each day women spend a combined total of at least 16 million hours collecting drinking water, men spend 6 million hours on this task, and children spend 4 million hours. This burden leaves women less time to engage in other activities, such as attending a school or participating in labor market. The situation is much worse in areas affected by conflict, where walking long distances to gather water or fuelwood often puts women and children in harm's way (UN 2018). 
One of the most worrying issues is food consumption. Food systems are part of peoples' everyday lives, but mainstream production and consumption patterns are contributing to unhealthy and unsustainable living. Food policies outlining biodiverse food cultures and futures are indispensable (World Business Council for Sustainable Development 2019).

It is revealed by Swiderska (2018) that women are safeguarding biodiversity - sustaining biodiverse farming by combining traditional knowledge and innovation to protect the local seed system. It is women, she said, who save and select the seeds of traditional crops (e.g. in the Peruvian Andes they have a much greater knowledge of native potato varieties). This means that women are more prominent in conserving local landraces, which are often better adapted to local environments and provide crucial options for adaptation to future climatic and market changes. Preserving traditional seeds is intrinsically linked to the food security, livelihoods, and culture of farming communities._Swiderska (2018) further explains that the role of women in local seed systems partly reflects the trends in many communities where men, particularly younger men, are moving to urban areas to find work. A new trend can be observed in some communities for men to focus more on commercial farming using modern practices and seeds, like hybrids, that can bring associated shifts towards monocultures that threaten biodiversity. Women play a greater role in sustaining biodiverse subsistence farming linked with responsibility for ensuring food security for the family.

Women are also active "stewards" in forests in many parts of India where they set and implement rules on wood and biomass collection, ensuring the forest reserves are used sustainably and equitably. They - once they are given the opportunity to decide - grow traditional crops that have high nutritive value and prefer diverse forest species that can be used for fuelwood, water recharge, and herb-based medicines. Sogani (2018) describes the special bond between women in India and the country's natural resources - a connection that positions them as key preservers and managers of biodiversity.

\section{Tension between gender groups}

It is understood from the reports, blogs, and interviews collected by the International Institute for Environment and Development (IIED) (2019) that while men's roles and responsibilities tend to connect them with the market and give more available access to information, women tend to be more restricted from such resources.

Men are more in touch with the outside world, and better informed about the latest technologies and practices in use. Their attitude to production is more profit-oriented - for giving enough support to the family and the community whereas, for the majority of women, the priority comes from the concern for feeding the family. They seem to be more cautious about introducing new methods or processes, e.g. hybrid seeds, pesticides, and fertilizers that threaten the sustainability of these resources (United Nations 2010).
Bolin (2018), the author of the article Biodiversity: a woman's business? indicates that in entrepreneurship women are the fastest growing group, whose role in safeguarding biodiversity cannot be ignored. She brings an example from Kenya, where the issue of women's participation in biodiversity protection goes beyond the forest landscape to the farm. In Kenya, both men and women grow trees on their farms to reduce water stress and make farming more sustainable. The government of Kenya through Farm Forestry Rules promoted farm forest cover at least $10 \%$ of every agricultural land holding. Landowning laws excluded women to achieve this target. Since half of the 1.5 billion people who depend on forest products and livelihood are women their economic activities in farm landscapes cannot be overlooked. Women - led enterprises together with women's grassroots organizations helped the women in Kenya in enterprise development related to timber production, setting up nurseries of indigenous tree species and eco-tourism. Bolin (2018) calls out the multiple benefits of providing women entrepreneurs with increasing support. While it helps rebalance gender opportunities in the policy and in the forest sector it also contributes to safeguarding biodiversity.

\section{Profiting from biodiversity}

Conservationists are rarely profit-oriented. Since the question of conservation, biodiversity, and ecology in general often raises ethical issues and contradicts business interests, the decision making is not progressing without compromises.

But there are some cases, described by Bolin, where business activities not only complement but even strengthen conservation efforts. In many communities in Congo, women collect and process non-wood forest products like leaves, fruits, nuts, oils, and honey, and use these goods as business products and sell them as cosmetics or household remedies and food. Their special knowledge is required to maintain sustainability: they make sure that these stocks can grow in the long run. Their activities do not always go smoothly: it can raise conflicts between men and women within the community as it was the case in Cameroon with the Moabi tree, a highly valued tropical hardwood. Men wanted to cut it and sell it for export while women wanted to keep them and use the bark for medical purposes, the fruits for food and the seed extract for cooking and skincare beauty products (Bolin 2018)

Economic aspirations of indigenous peoples are supported by IIED groups in Myanmar, Nepal, and Cameron where women are given training offered by the Women Entrepreneurs Development Fund to organize and lead enterprise activities that help conserve the forests. Also, enterprise development plan is made to support decision making and elaborate social and environmental strategies that promote both environmental and social strategies. In such a way a wider range of forest products can be utilized while ensuring forest resources are used sustainably and fairly by both gender groups (Bolin 2018). 


\section{Decision-making: Gender restrictions}

Women need to be involved in processes to converse and sustainably use biodiversity because they play a significant role as primary land managers and resource users. They often use natural resources differently from men and yet often have minimal influence on how local resources are managed. An increasing demand is that empowering more women in localresource and decision-making may lead to better resource governance and conservation. For example, in forestry and fisheries sectors in India and Nepal there is strong evidence to suggest that including women in forest and fishery management groups can result in better resource governance and conservation outcomes (Leisher et al., 2016).

Agribusiness investments like expanding land markets have the potential to benefit local communities, and - according to research - they also often impact vulnerable groups such as women. Changes in land use - traditionally used by women can result in women being discarded, working longer hours, which reduces the time they can spend generating more income or taking part in education. And it is not only them who have to be educated about new farming methods and technology but on the other side their knowledge and expertise should be spread around and passed on from generation to generation. Social learning spaces are crucial for embedding this vision in practical actions in community schools and other educational institutions. Therefore, environmental sustainability, conservation of biodiversity, agricultural production structures, environmental and social legislation should be managed in one holistic system (Fig. 2).

Biodiversity needs to be understood with due attention given to the distinct roles played by women in the society. Women are often more marginalized in decision-making processes both in private and public level. Although their biological roles as wives and mothers in the household require to develop special knowledge and skills with reference to biodiversity, this expertise is not acknowledged or relied on in the community or higher levels. Women are in a unique position to bring different perspectives and new solutions to address biodiversity their opinions remain unheard. Even if they have women representatives in conservancy management, the voices of their male counterparts are stronger. Even the highly qualified female experts are inclined to accept the traditional gender roles. As a young woman undertaking a senior role in Namibia conservancy movement said:" I have learned there are traditional relationship dynamics that I have to respect and remain cognizant of. I believe conservation requires an understanding of the traditions underpinning the lives and decision making of communities" (International Institute for Environment and Development 2018).

At the same time, some changes can be expected. Over half of countries have policies or procedures for the participation of women in rural water supply. Policies and procedures for participation by local governments in the management of water and sanitation can help to ensure that communities are informed, consulted and represented in the delivery of these vital services. Data for 110 countries from two surveys - in 2014 and 2017— show that 85 per cent of countries reported that they have policies or procedures in place for the participation of local communities in the management of rural water supply, 81 per cent have the same for rural sanitation, and 79 per cent for urban water supply and sanitation. The role of women's participation is increasingly important as a measure of equity. Among the 84 countries participating in the 2017 survey, the number of countries that had policies specifically mentioning women's participation is higher for rural communities than for urban areas (United Nations, 2018)

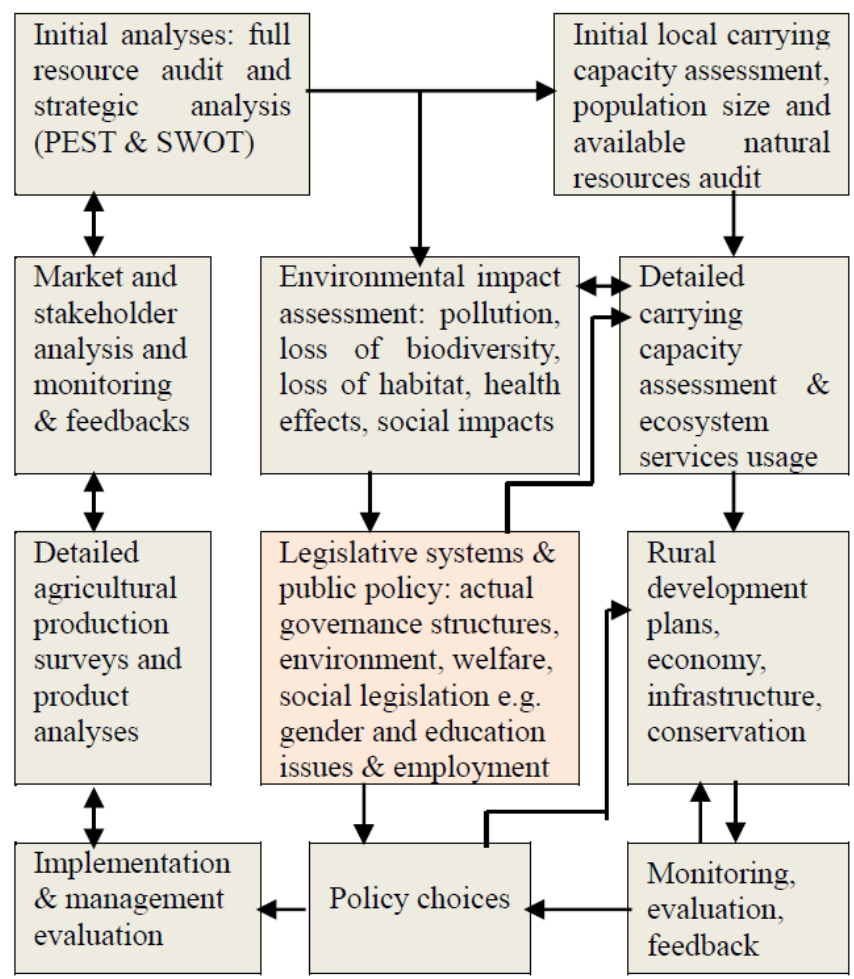

Figure 2. Management structures of sustainable agricultural production including the use of natural resources, biodiversity, environmental, economic and social carrying capacity, legislation (including gender issues)

\section{CONCLUSIONS}

Indigenous people - especially women, have a wealth of traditional knowledge, skills, and practices, that can sustainably protect and conserve biodiversity. They are traditionally, closely connected with natural resources, and their informal management, which stems from being principally responsible for the subsistence of their families, and the need to secure resources to fulfil this responsibility. In order to achieve the Sustainable Development Goals (United Nations 2018) by 2030, it must be ensured that there is a political will for mainstreaming gender in the implementation of the Convention on Biological Diversity (United Nations 1992). How can biodiversity be saved from a crash as one of the deepest global crises of the 21 st century? The solution: more needs to be done to ensure that women's voices are heard equally strong and their views represented 
when it comes to local, regional, national or international policy making. The vital role of women and the need for their full and equal participation and leadership in all areas of sustainable development was reaffirmed in paragraphs 236 to 244 in The Future We Want (United Nations 2012), as well as in the Open Working Group Proposal for Sustainable Development Goals (United Nations 2014).

More female representatives from the highest to the lowest legislative bodies would be beneficial to support the interest of the stakeholders, their majority - especially at the effective farming end - are women. There is a high demand on their creative energies, disruptive knowledge and innovative solutions on these direct conservation methods of biodiversity who have a deep and abiding cultural and spiritual relationship with ancestral territories and the ecosystems that support them.

Giving voice to women in biodiversity policy and programmes will not only ensure that the crucial agrobiodiversity agenda is effectively addressed but will also promote development-oriented biodiversity conservation approaches that are needed to mainstream biodiversity into agriculture and development sectors

According to the United Nations Sustainability Development Goals (2018), awareness raising, and trainings should be provided on the links between gender and biodiversity to interested staff, indigenous and local communities, and policymakers. It is essential to enable women's full engagement in biodiversity decisions and to ensure that biodiversity conservation efforts are successful in the long run. Besides, biodiversity conservation approaches need to be promoted with reliance on traditional conservation approaches applied by women.

Without the contribution and thorough involvement of women in the sustainable use of resources the root-causes of biodiversity loss will remain unsolved, gender-inequality problems deepened.

\section{REFERENCES}

Bolin, Anna (2018) Biodiversity: A women's business? https://www.iied.org/biodiversity-womens-business (Accessed on December 11, 2019)

Brown, M. E. and Funk, C. C., (2008): Food Security Under Climate Change NASA Publications. 131.

http://digitalcommons.unl.edu/nasapub/131

Collins Johnson, N. (1993): Can Fertilization of Soil Select Less Mutualistic Mycorrhizae? Ecological Applications. Vol. 3, No. 4 (1993), pp. 749-757

DOI: $10.2307 / 1942106$

Eisenhauer, N. (2018): Aboveground-belowground interactions drive the relationship between plant diversity and ecosystem function. Research Ideas and Outcomes, 4:e23688. DOI: $\underline{10.3897 / \text { rio.4.e23688 }}$
International Institute for Environment and Development (2018) Q\&A: Community-based natural resource management is the future.

https://www.iied.org/qa-community-based-natural-resourcemanagement-future (Accessed on December 11, 2019)

International Institute for Environment and Development (2019) Women champions of biodiversity. https://www.iied.org/women-champions-biodiversity (Accessed on December 11, 2019)

Jaworski, Nicole (2019) For water systems that work, look to women.

https://www.citylab.com/environment/2019/03/safedrinking-water-women-leaders-jobs-report-data/584386/ (Accessed on December 11, 2019)

Leisher, Craig; Temsah, Gheda; Booker, Francisca; Day, Michael; Samberg, Leah; Prosnitz, Debra; Agarwal, Bina; Matthews, Elizabeth; Roe, Dily; Russell, Diane; Sunderland, Terry, Wilkie, David (2016) Does the gender composition of forest and fishery management groups affect resource governance and conservation outcomes? A systematic map. Environmental Evidence 5:6.

DOI 10.1186/s13750-016-0057-8

https://environmentalevidencejournal.biomedcentral.com/tra ck/pdf/10.1186/s13750-016-0057-8 (Accessed on December 11, 2019)

Némethy, S. \& Szemethy, L. (2019): The sustainability of woody biomass feedstock production and landscape management: land use, phytoremediation, biodiversity, and wildlife habitats. Ecocycles, Vol. 5. no. 1.

DOI: 10.19040/ecocycles.v5i1.141

Roe, Dilys; Seddon, Nathalie; Elliott, Joanna (2019) Biodiversity loss is a development issue. A rapid review of evidence.

https://pubs.iied.org/pdfs/17636IIED.pdf (Accessed on December 11, 2019)

Sogani, Reetu (2018) Q\&A: Women in rural India are nature's guardians.

https://www.iied.org/qa-women-rural-india-are-naturesguardians (Accessed on December 11, 2019)

Swiderska, Krystyna (2018) Q\&A: Why indigenous seedsaving women are the stewards of biodiversity.

https://www.iied.org/qa-why-indigenous-seed-savingwomen-are-stewards-biodiversity (Accessed on December 11, 2019)

The Economist Intelligence Unit (2019) Food Sustainability Index.

http://foodsustainability.eiu.com/international-womens-daygender-gap-farming-hampering-progress-towards-zerohunger-targets/ (Accessed on December 11, 2019)

United Nations (1992) Convention on Biological Diversity. 
https://www.cbd.int/doc/legal/cbd-en.pdf (Accessed on December 11, 2019)

United Nations (2010) Achieving gender equality, women's empowerment and strengthening development cooperation. https://www.un.org/en/ecosoc/docs/pdfs/1050143 (e) (desa)dialogues ecosoc achieving gender equa lity women empowerment.pdf (Accessed on December 11, 2019)

United Nations (2012) The Future We Want. https://sustainabledevelopment.un.org/content/documents/73 3FutureWeWant.pdf (Accessed on December 11, 2019)

United Nations (2014) Open Working Group Proposal for Sustainable Development Goals.

https://sustainabledevelopment.un.org/content/documents/15 79SDGs\%20Proposal.pdf (Accessed on December 11, 2019)

United Nations (2015). Gender Equality and women's empowerment.

https://www.un.org/sustainabledevelopment/genderequality/ (Accessed on December 11, 2019)

United Nations (2018) The Sustainable Development Goals Report.

https://unstats.un.org/sdgs/files/report/2018/TheSustainable DevelopmentGoalsReport2018-EN.pdf (Accessed on December 11, 2019)
United Nations (2019a) Goal 5: Achieve gender equality and empower all women and girls.

https://www.un.org/sustainabledevelopment/genderequality/ (Accessed on December 11, 2019)

United Nations (2019b) The Zero Hunger Challenge. https://www.un.org/zerohunger/ (Accessed on December 11, 2019)

United Nations Population Fund (2015) Transforming Our World: The 2030 Agenda for Sustainable Development. https://www.unfpa.org/resources/transforming-our-world2030-agenda-sustainable-development (Accessed on December 11, 2019)

World Business Council for Sustainable Development (2019) Our global food system is unsustainable, unequal, destabilizing and unhealthy. https://www.wbcsd.org/Programs/Food-and-Nature/FoodLand-Use/FReSH/News/Our-global-food-system-isunsustainable-unequal-destabilizing-and-unhealthy (Accessed on December 11, 2019)

World Economic Forum (2018) The Global Gender Gap Report.

https://www.weforum.org/reports/the-global-gender-gapreport-2018 (Accessed on December 11, 2019)

(C) 2019 by the author(s). This article is an open-access article distributed under the terms and conditions of the Creative Commons Attribution (CC-BY) license (http://creativecommons.org/licenses/by/4.0/). 